J. Dairy Sci. 100:850-850

https://doi.org/10.3168/jds.2017-100-1-0850

(c) American Dairy Science Association ${ }^{\circledR}, 2017$.

\title{
Corrigendum to "Particle length of silages affects apparent ruminal synthesis of B vitamins in lactating dairy cows" (J. Dairy Sci. 99:6229-6236)
}

\author{
D. S. Castagnino, K. L. Kammes, M. S. Allen, R. Gervais, P. Y. Chouinard, and C. L. Girard
}

In this paper, we used erroneous values for the molecular weight of thiamin and vitamers of vitamin $\mathrm{B}_{6}$. This error had limited effects on the overall results or statistical significance; however, several values reported in the text and tables are incorrect. The error affected statements in the Daily Intake, Apparent Ruminal Synthesis, and Duodenal Flow subsection (page 6232-6235) of the Results and Discussion, as well as values of thiamin and vitamin $\mathrm{B}_{6}$ reported in Table 1 (page 6231), Table 2 (page 6232), Table 3 (page 6233), Table 4 (page 6233), and Table 5 (page 6234).

A revised version of this paper containing the corrections noted above has been published as supplementary data (see file below).

The authors regret the errors.

Supplementary Data: Corrected Article

View File

\section{REFERENCES}

Castagnino, D. S., K. L. Kammes, M. S. Allen, R. Gervais, P. Y. Chouinard, and C. L. Girard. 2016. Particle length of silages affects apparent ruminal synthesis of B vitamins in lactating dairy cows. J. Dairy Sci. 99(8):6229-6236. 10.3168/jds.2016-11274. 